\title{
STUDIES ON THE SWIMMING NOISE OF THE FISH
}

\author{
Michio Uno and Tuneo Konagaya* \\ Received Aug. 2, 1960
}

\section{Introduction}

Many notable studies on the sound produced by the various fish have been made. Miyake" conducted an exploratory observation about Yellowfin tuna, Neothunnus albacora (Lowe), and it was followed by Hashimoto, Nishimura, and Maniwa ${ }^{213)}$ who could detect the fish school by listening to their swimming sound.

If the fish are sensitive enough to recognize each other by listening to the sound produced by another, they might utilize this to chase their food animals and to escape from their enemies.

And also we might be able to apply this in fishing or angling by attracting the fish by using the proper sound.

This print deals with the preliminary experiment of the noise of a single and schooled fish during their swimming.

\section{Material and Method}

The first experiment was conducted in a wooden trough of $20 \times 30 \times 20 \mathrm{~cm}$ which

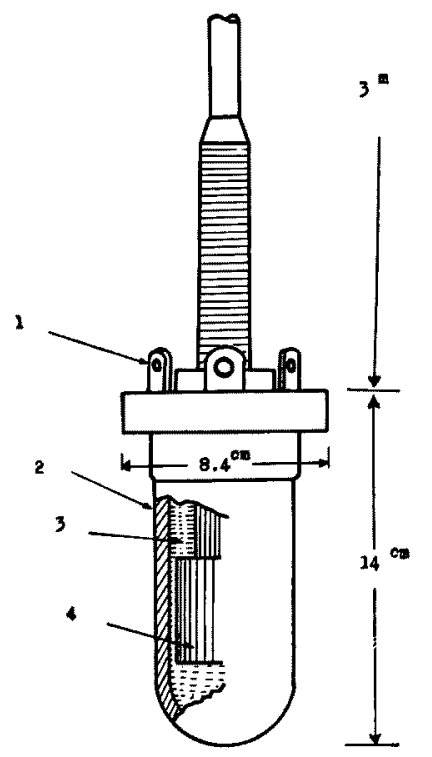

Fig. 1.: 57-TA Hydrophone

1: hanging ring 2 : rubber

3: caster oil 4: chitanic acid
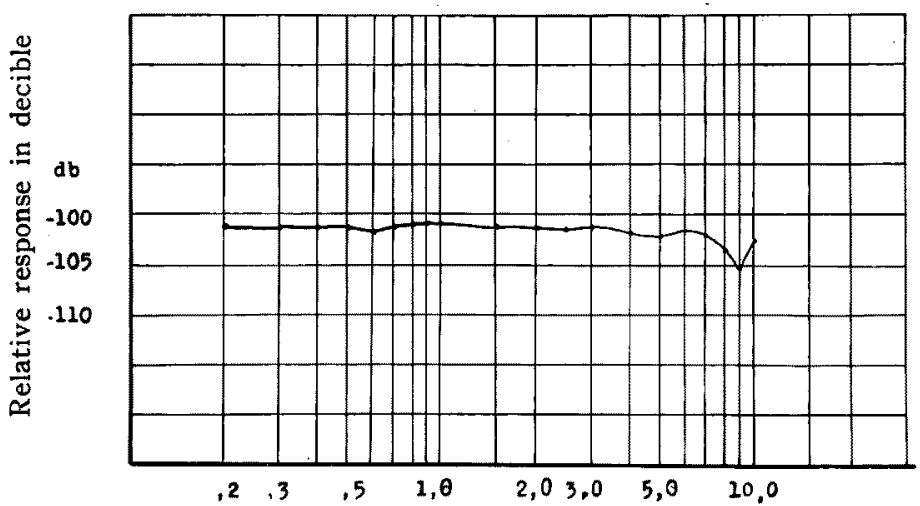

Fig. 2. Frequency.responses of characteristic 57-TA hydrophone.

contained a silver carp, Carassius auratus (Linné) (13 $\mathrm{cm}$ in length). The sound measuring equipment consisted of hydrophone (Fig. 1, 2), preamp (Model 57TA), oscilloscope (Model CO-130), Yashica $8 \mathrm{~mm}$ cinecamera, and flash gun.

The reception range of sound was about 100 to 10,000

* Prefectural University of Mie, Otanimachi, Tsu, Mie Prefecture 
cycles per second. During these experiments the hydrophone was suspended $5 \mathrm{~cm}$ below the surface close to a trough corner. The fish was stimulated by 60 cycles of AC 20 volts. The behavior of the fish was photographed, using $8 \mathrm{~mm}$ cine-camera at the speed of 33 frames per second. At the time of measuring, flashing was given to both the cine-camera and the oscilloscope simultaneously in order to mark the signal for synchronizing. The relation between the movement of the fish and the swimming noise was observed from both records.

Secondarily, the swimming sound of trout, Salmo gairdnerii irideus (Gibbons) in school was recorded by using the tape-recorder. The sound measurement equipment used was sensible to approximately 100 to 9,000 cycles per second. This experiment was performed at the Fish-Farm of the Tokyo University of Fisheries at Oizumi, Yamanashi Prefecture. This fish pond was made of concrete and was $5 \times 26 \mathrm{~m}$ in width and 1.0 $\mathrm{m}$ in depth. Water temperature was $10.5^{\circ} \mathrm{C}$. The hydrophone was suspended $50 \mathrm{~cm}$ below the surface in the center of the pond. About 4,000 rainbow trout were kept in this pond.

We also observed the swimming noise of the yellow-tail, Seriola quinqueradiata Temminck et Schlegel, in Kuki bay, Mie Prefecture. The yellow-tail $(30 \mathrm{~cm}$ in length, 3,000 fish) were kept in the cylindrical crawl made of cremona net. The size of the crawl was $3.9 \mathrm{~m} \times 3.9 \mathrm{~m}$ in width and $3.6 \mathrm{~m}$ in depth. Sea water temperature was $22.0^{\circ} \mathrm{C}$. The swimming noise was recorded using the same method as that at Oizumi.

Finally, the under water noises of the angling, engines and sprinkler of the skipjack-fishing boat, Fujimaru (191 GT, 380 HP), which belonged to the Shizuoka Fisheries Experiment Station, were recorded as well.

These experiments were conducted during 1958 to 1959.

\section{Results and Consideration}

Fig. 3 shows the oscillogram of the under water sound pressure wave produced by the movement of a single fish. As shown in Fig. $3-(B),(C)$, and (D) when the sound was produced by the fish passing just below the surface of the water, sometimes the fins of the fish were exposed and the fish jumped up from the water. But as in Fig. 3-(A), no sound was catched when the fish swam perfectly below the surface.

Figs. 4, 5, and 6 indicates the oscillogram and sonograph of underwater sound pressure wave produced by 4,000 rainbow trout. As shown in Fig. 4- (A), (B), and Fig. 6, as the fish school approached the hydrophone, the sound was distinctly noticeable over the back ground noise and it was a little like the jet stream spouting from a small hole. It seemed that the Doppler Effect was recognized in it. These noises, recorded, contained the frequency of about 500 to 5,000 cycles per second.

When the fish school was jumping up and preying around the hydrophone, as shown in Fig. 4- (C) and (D), the sound contained about 2,000 to 3,000 cycles per second. Fig. 4-(E) and Fig. 6 show the sound caused by the sudden movement of 


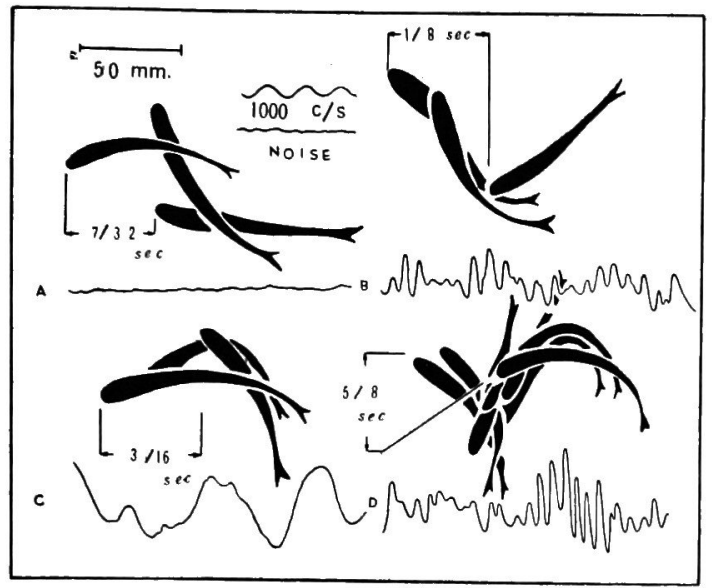

Fig. 3. Oscillograms of the under water sound pressure wave produced by the movement of a fish.

(A': swimming noise (B): noise produced with the fin appeared above the surface of the water (C): swimming noise produced under the surface of the water (D): noise produced by the fish jumping.

the tail of the fish. This sound contained the frequency of 400 cycles per second. This sound might be caused by the fish beating each other or the concrete bottom with their tails.

Fig. 7: shows the oscillogram of under water sound pressure wave produced by yellow-tail. Fig. 7-(A) shows the under water noise of the crawl. Fig. 7-(B), (C),

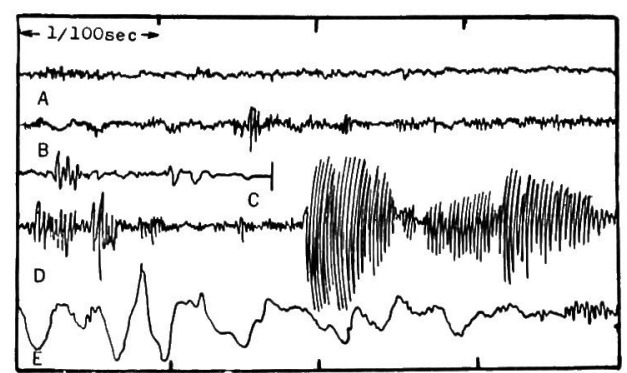

Fig. 4. Oscillograms of the under water sound pressure wave produced by 4,000 rainbow trout. (A): approach to hydrophone $(4,000$ trout (B): nearer the hydrophone (C): The noise produced just when the fish took a prey. (D): jumping around the hydrophone (E): sudden movement.

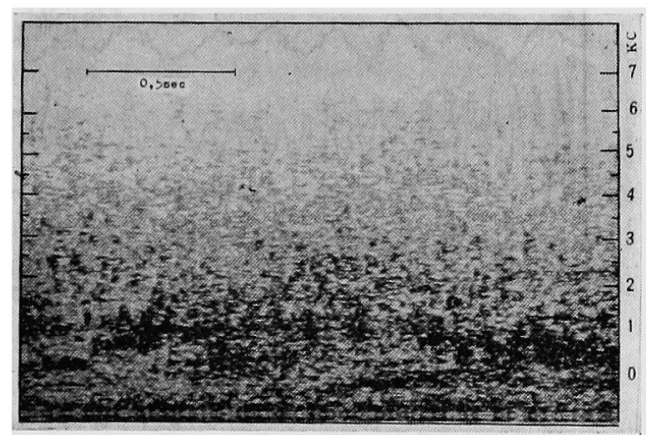

Fig. 5. Sonograph of the under water sound produced by the sudden movement of the fish.

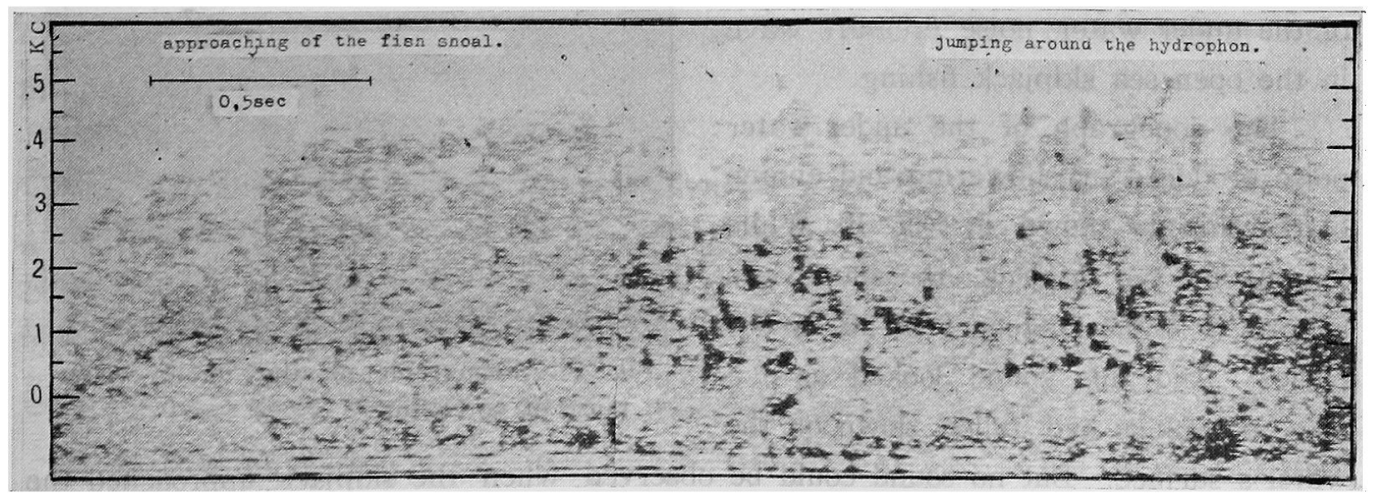

Fig. 6. Sonograph of the under water sound produced when 4,000 trout approached the hydrophone. 


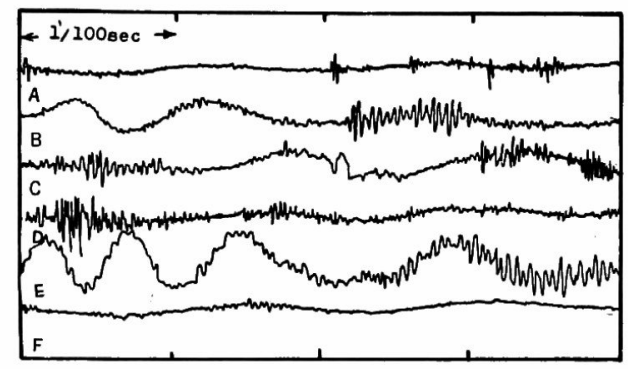

Fig. 7. Oscillograms of the under water sound pressure wave produced by, 3,000 yellow-tail and noise of the fish under the crawl. and (D) indicates the under water noise that the fish school produced while swimming at the surface of the water. These sound resembled the sound of a ripple it they must have originated in the net movement caused by the swimming of the fish school.

But this noise could not be heard with the trout. Fig. 7-(E) shows the noise produced by the preying of the fish school. The under water noise of the set net was shown in Fig. 7-(F), and in this case only a little back ground noise was recorded.

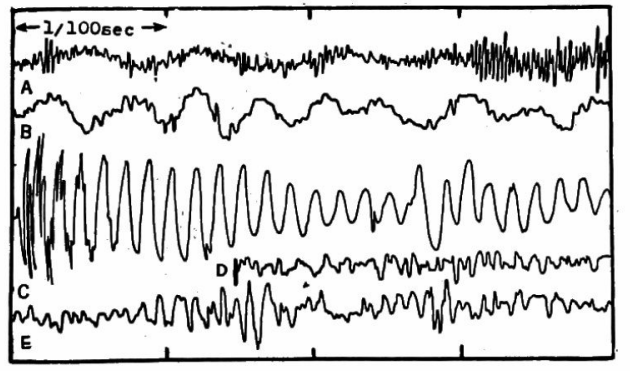

Fig. 8.

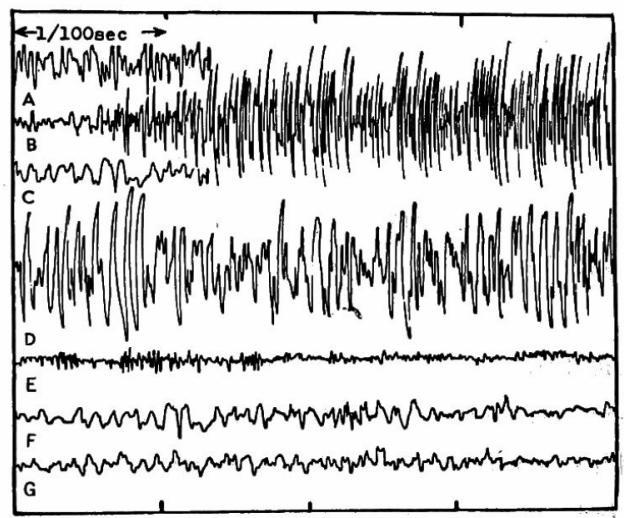

Fig. 9.

Oscillogram of the under water noise pressure produced by skipjack fishing in the open sea. Fig. 8. (A): under water noise produced by stern (B), (C): under water noise of skipjack angled (D): sound in sardine crawl Fig. 9. (A): sound produced when an anchor was dropped $(B)$ : propeller noise (C): skipjack angling at the stern (D): noise of sprinkling.

Figs. 8 and 9 show the oscillogram of the under water noise pressure wave in the open sea skipjack fishing.

The sonograph of the under water noise produced by showering and engine of the ship is shown in Fig. 10. While angling for the skipjack, the sound was composed of the frequency of 200 to 600 cycles. And this sound looked as if a large substance had fallen down on the

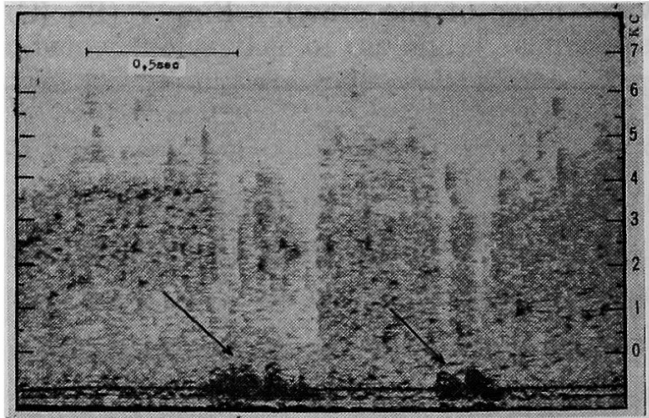

Fig. 10. Sonograph of the under water noise of sprinkling water's surface. But no sound could be observed when the skipjack approached the prey. 
When the fishing boat was operating, the noise recorded in the water was very loud, and the sound pressure of showering was very high.

Therefore, the effect of showering in fishing must stimulate the auditory sense as well as the visual sense of the fish.

\section{Summary}

The swimming noise of a single fish and a fish school was studied.

(1) Single fish: The sound was produced when a fish swam just below the surface of the water or jumped up from the water, but could not be detected when it swam under water.

(2) Fish school: When the fish school was approaching the hydrophone in a pond, the sound was distinctly noticeable over the back ground noise. But in yellowtail crawl, it was not heard. In a pond or crawl, certain low frequency sounds were produced by sudden movements, jumping, and preying of the fish.

(3) Skipjack fishing: When a skipjack was angled, the sound was observed, but it was not observed when they were approaching the prey. In operating the fishing boat, the noise was very loud, and the sound pressure produced by showering was very high.

\section{Acknowledgement}

In closing this paper we wish to acknowledge our indebtedness to several institutions and persons for their support of our work. We are indebted as well to Professor Ishi for much valuable advice during the work, and we wish to express our thanks to Professor Kuroki, Mr. Maniwa and Eguchi, for very helpfull suggestions and criticisms in regard to the problems. Further, we also wish to express our thanks to $\mathrm{Mr}$. Shikata and Mr. Matsui of the CBC Radio Broadcasting Station and to Mr. Uemura and Mr. Tokita of Sony Company, and to Mr. Sekino, Mr. Tukakoshi of Shizuoka Fisheries Experiment Station.

The expentions of this investigations was defrayed in part by a research fund granted from the Ministry of Education,

\section{References}

1) Iwao Miyake: Special Scientific Report; Fisheries No. 91 Part 3.

2) T. Hashimoto, M. Nishimura and Y. Maniwa: Tech. Rep. Fishing Boat., 10, (1957).

3) T. Hashimoto, M. Nishimura and Y. Maniwa: Bull. Jap. Soc. Sci. Fish., 26, 245-249 (1960). 